\title{
RNA multimerisation in the DNA packaging motor of bacteriophage $\phi 29$
}

\author{
JONATHAN P. A. WOOD $\uparrow$, STEPHANIE A. CAPALDI $\$$, MARK A. ROBINSON, ANDREW J. BARON and NICOLA J. STONEHOUSE*
}

Faculty of Biological Sciences and Astbury Centre for Structural Molecular Biology, University of Leeds, Leeds, LS2 9JT, UK

\begin{abstract}
The use of bacteriophages as experimental tools allows the investigation of interactions between components at the molecular level that are often not possible in more complex virus systems. The bacteriophage $\$ 29$ acts as a molecular machine to package its own genomic DNA during viral assembly. Self-associating RNA molecules, called pRNA, have an essential role in the function of this machine. This paper reports the characterization of this self-association (which leads to multimerisation of wild-type and truncated variant pRNAs) by analytical ultracentrifugation (including determination of the partial specific volume of the pRNA), together with an investigation into the domains of the molecule important for multimerisation by the use of complementary DNA probes.
\end{abstract}

Keywords: RNA; Bacteriophage $\$ 29$; Molecular motor; Virus assembly; Analytical ultracentrifugation; Partial specific volume

\section{Introduction}

Viruses are obligate intracellular parasites and have been identified in a wide range of hosts, from bacteria to higher eukaryotes. Despite the diversity in host range, infection mechanism and lifecycle, some common themes exist. All viruses are composed of a shell (or capsid), serving to encapsidate and protect the viral genome. Viral capsids can be relatively simple or complex, multi-layered structures. In all cases, however, the shells are composed of multiple copies of the same molecules and their morphology is based on mathematical principles, resulting in structures displaying elements of either helical or icosahedral symmetry.

Because of the available structural data, we have a good understanding of the diversity of the organisation of protein subunits in the shells of many viruses. However, our knowledge of the processes involved in forming these shells is very limited. Such studies of virus assembly are hampered by the problems associated with the study of transient intermediates. One of the critical stages in the assembly of any virus is genome packaging, i.e. the recognition and packaging of the viral genome by the components of the shell. There are two mechanisms by which this can occur. Viruses like bacteriophage MS2 use nucleated assembly, where a specific interaction between protein subunits and the RNA genome results in recruitment of further subunits to enclose the RNA [1-3] (and the article by Stockley et al. in this issue). In contrast, viruses such as $\phi 29$, a bacteriophage of Bacillus subtilis, use an alternative ATP-dependent strategy to package their genomic DNA. In this case, DNA is actively packaged into a preformed shell, with components of the virus acting as a molecular motor. DNA is thought to be packaged via a portal or connector structure, located at one of the five-fold vertices of the capsid shell (here referred to as a prohead or procapsid). A similar structure has recently been reported in herpes virus [4] and it has been proposed that viruses such as herpes and adenovirus use a similar mechanism to package their genomes.

The $\phi 29$ motor comprises several components; the virus prohead (incorporating the connector, gp10), multiple copies of an ATPase (gp16) and molecules of RNA called pRNA (prohead RNA) [5] as shown in figure 1(A). This pRNA is a 174 nucleotide molecule, however a 120 nucleotide variant, truncated at the $5^{\prime}$ and $3^{\prime}$ termini (figure 1(B)), is also functionally viable in the packaging process [6]. The proposed secondary structure of pRNA is a three-helix junction, with two stem-loops (one containing the $\mathrm{CE}$ and $\mathrm{E}$ loops and the second, the D loop) and a long base-paired helix (A). There are 4 bases in the upper or $\mathrm{CE}$ loop (45-AACC-48) that are complementary to the lower,

$\dagger$ Present address: Materials Today, Elsevier, The Boulevard, Langford Lane, Kidlington, OX5 1GB, UK.

$\$$ Present address: Department of Molecular and Cell Biology, 227 Hildebrand Hall \#3206, University of California, Berkeley, Berkeley, CA 94720, USA.

*Corresponding author. Tel: +44-113-343-3102. Fax: +44-113-343-2835. Email: n.j.stonehouse@leeds.ac.uk

Journal of Theoretical Medicine

ISSN 1027-3662 print/ISSN 1607-8578 online (C) 2005 Taylor \& Francis Group Ltd

http://www.tandf.co.uk/journals

DOI: $10.1080 / 10273660500149802$ 
(A)

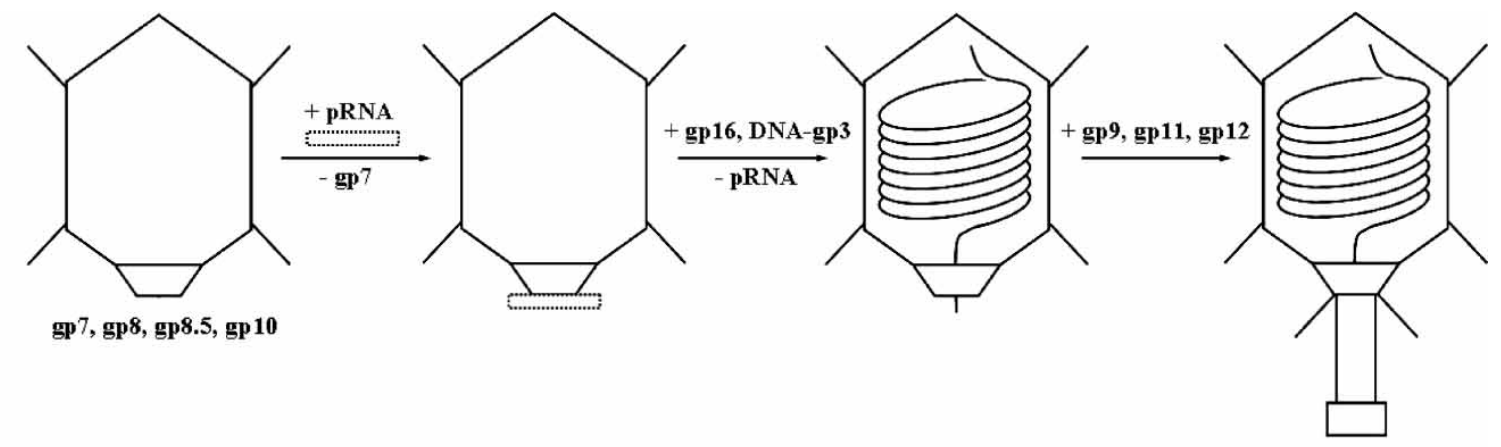

(B)
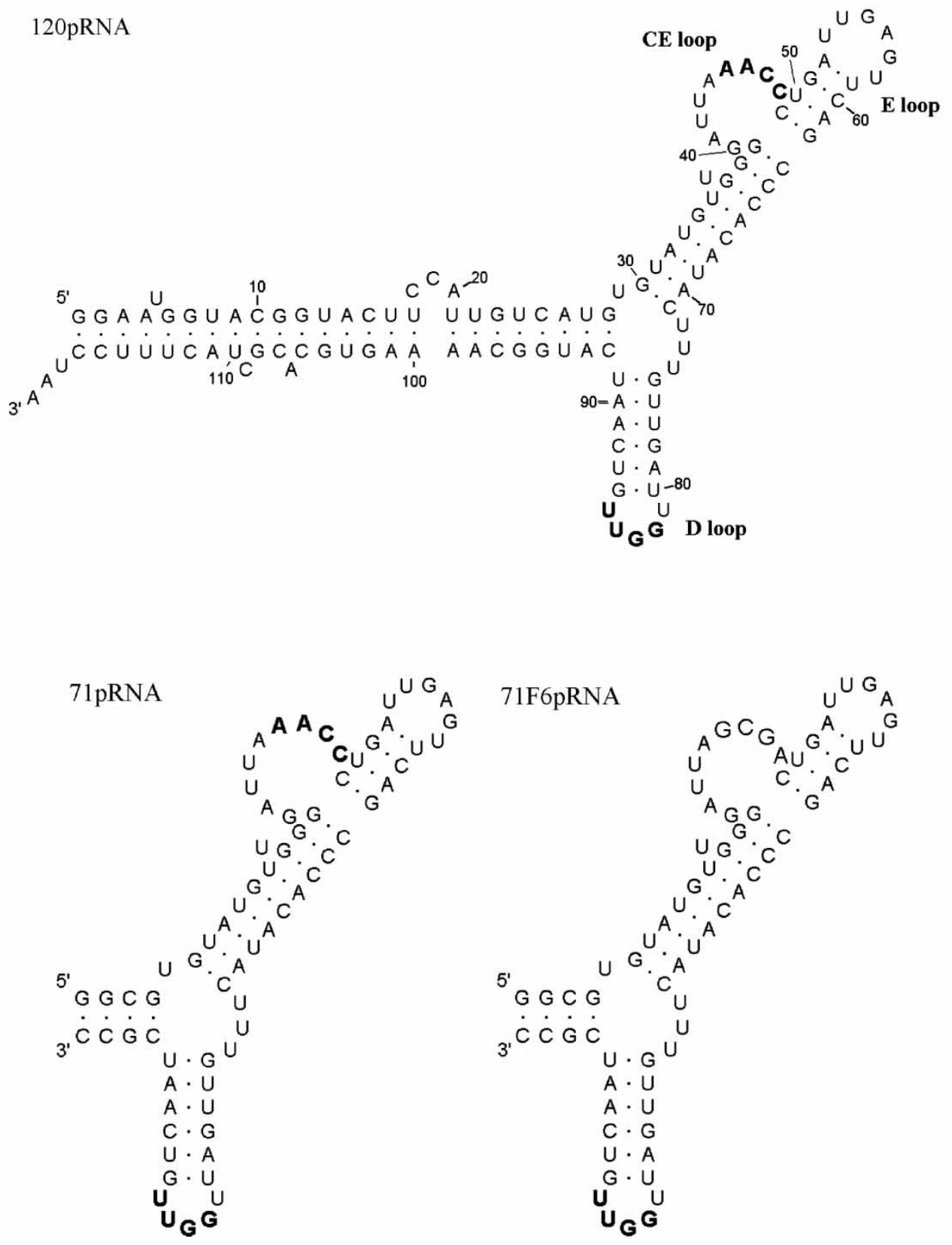

Figure 1. Schematic representation of the components of bacteriophage $\phi 29$ implicated in the packaging of genomic dsDNA (A) gp7 $=$ scaffold protein; gp8 = major capsid protein; gp8.5 = head fibre protein; gp10 = connector protein; pRNA = prohead RNA; gp $16=$ ATPase; DNAgp3 = genomic DNA-protein complex; gp9 = tail protein, gp11 = collar protein; gp12= appendage/anti-receptor protein. The MFold calculated secondary structure of $\phi 29$ pRNA sequences used in this study (B) 120pRNA is shorter than the wild type $\phi 29$ 174mer pRNA but retains full $\phi 29$ genomic dsDNA packaging activity. 71pRNA is a shortened version of 120pRNA, with identical loop structure, whilst 71F6pRNA is modified to remove base pairing between CE and D loops (complementary bases involved in pRNA multimerisation are in bold). Neither 71pRNA nor 71F6pRNA are competent to package $\phi 29$ genomic dsDNA. 
D loop (82-GGUU-85). It is thought that pRNA molecules self-associate during packaging of the DNA, involving intermolecular base-pairing of some or all of these complementary bases, and that magnesium ions are necessary for the process $[7,8]$. Packaging of the $7 \mu \mathrm{m}$ long linear, double-stranded $\phi 29$ genome is proposed to take less than $6 \mathrm{~min}$, with the motor working at forces estimated to reach $50 \mathrm{pN}$ [9]. Once packaging is complete, pRNA and ATPase molecules dissociate and viral lower collar, tail and appendage proteins are added to form virulent phage particles [5] (figure 1(A)).

RNA molecules perform a range of diverse functions in the cell, including roles in gene expression and catalysis, and the role of RNA in a viral DNA packaging motor is relatively recently documented. Similar pRNAs have been identified in phages that are related to $\phi 29$ [10] although it remains to be determined if comparable molecules are found in a wider range of viruses that package DNA into preformed shells.

The $\phi 29$ connector is composed of a ring of 12 molecules of gp10 [11,12]. The X-ray crystal structure of the complex reveals a funnel-like structure, approximately $75 \AA ̊$ in height, incorporating a central channel (of variable internal dimensions in excess of $35 \AA$ ) through which DNA is translocated [11, 13]. Despite co-crystallisation with pRNA, no density for pRNA was detected by this analysis [14]. 3D cryo-electron microscopy reconstructions of assembling virus particles have revealed density ascribed to pRNA at the narrow end of the structure, although the pRNA multimerisation state during interaction with the connector is a matter of debate. Two studies have independently modelled pentameric [13] and hexameric [15] pRNA species, and the latter model is also supported by a large amount of biochemical evidence $[8,16]$.

The multimerisation state of pRNA has implications for the mechanism of motor function. In the 1970s, Roger Hendrix published a model of symmetry mismatch to explain DNA packaging in bacteriophages [17]. This relies on the presence of differing symmetries of the multimeric components of a rotary motor, thereby preventing energy minima (or motor stalling) during rotation. A hexameric pRNA would therefore be unlikely to rotate with respect to a dodecameric connector, without significant energy input to promote conformational change, although a pentameric pRNA could achieve symmetry-mismatch-related rotation. It is also possible that the motor functions without rotation, perhaps exploiting a ratchet-based mechanism [18].

\section{Primary objective and research design}

In this paper, we report an investigation into the selfassociation of pRNA in solution, using the technique of analytical ultracentrifugation (AUC) [19]. AUC allows the investigation of multimerisation of species in solution and also an analysis of the affinity of interactions involved in self-association. In particular, equilibrium sedimentation experiments in the analytical ultracentrifuge have been used to obtain an accurate measure of the partial specific volume $\bar{v}$ of pRNA. Little data have been published in the literature regarding values of $\bar{v}$ for RNA molecules, those reported are in the range $0.46-0.58 \mathrm{ml} / \mathrm{g}$ [20]. For example, the $\bar{v}$ of $16 \mathrm{~S}$ ribosomal RNA from $E$. coli was determined to be $0.577 \mathrm{ml} / \mathrm{g}$ by densimetry [21]. Other reports have used calculated values of $0.588 \mathrm{ml} / \mathrm{g}$ [16] and $0.50-0.55 \mathrm{ml} / \mathrm{g}$ [22] based on experimental data for DNA. This paper therefore describes the techniques used to determine $\bar{v}$ for pRNA and the results obtained. This $\bar{v}$ value has been used for the analysis of further AUC experiment data investigating multimerisation of pRNA species in solution. In addition, the conformation and multimerisation of pRNA has been probed using short DNA oligomers with sequences complementary to regions of the pRNA molecule.

\section{Methods and procedures}

\subsection{Synthesis of pRNA}

Plasmids bearing templates for the in vitro transcription of 71pRNA and 120pRNA were prepared by the ligation of PCR-produced templates into pGEM-T Easy (Promega Corporation). A plasmid bearing template 71F6pRNA was prepared by the site-specific PCR mutation of the 71pRNA template plasmid. The identity of all clones was confirmed by DNA sequencing. DNA templates were excised and amplified by PCR. The RNAs were produced by $\mathrm{T} 7$ in vitro transcription according to manufacturers' instructions (Promega Corporation) and purified by denaturing polyacrylamide gel electrophoresis. The molecular weight of RNA oligonucleotides was confirmed using electrospray ionisation mass spectrometry according to a published method [23].

\subsection{Analytical ultracentrifugation}

Samples of 71F6pRNA and 71pRNA were prepared in dialysis equilibrium with buffers as indicated in the outcomes and results section. Equilibrium sedimentation experiments were carried out at $14^{\circ} \mathrm{C}$ using an Optima XLI analytical ultracentrifuge (Beckman). AUC cells with six-sector centrepieces and quartz windows were placed in a balanced An-60 Ti or An-50 Ti rotor. Samples were initially spun at $3000 \mathrm{rpm}$ and the absorbance recorded to verify sample loading concentration, then at a series of increasing rotor speeds, allowing equilibrium to be reached at each speed. Absorbance scans were obtained at regular intervals, and equilibrium judged to have been reached when scans did not alter with time. An overspeed run at 45,000 rpm was carried out to deplete the meniscus of all sedimenting species and determine baseline offset values. Data for different RNA loading concentrations were selected at each rotor speed and fitted using Optima XL-A/XL-I data analysis software (Beckman). The program Sednterp [24] was used to calculate buffer densities and viscosities at different experimental temperatures. 


\subsection{DNA synthesis}

The DNA oligonucleotides CE loop DNA, D loop DNA, CE helix DNA and 7mer DNA were prepared by solid phase phosphoramidite synthesis on an Expedite Nucleic Acid Synthesis System (Applied Biosystems) [25]. Purification by ion exchange high performance liquid chromatography (NucleoPac column, Dionex, $50 \mathrm{mM} \rightarrow 1 \mathrm{M} \mathrm{NH}_{4} \mathrm{Cl}$ gradient at $55^{\circ} \mathrm{C}$ ) yielded the desired products.

\section{Outcomes and results}

\subsection{Determination of partial specific volume of pRNA}

In investigating self-associating species using equilibrium sedimentation experiments in the analytical ultracentrifuge, the partial specific volume $\bar{v}$ of the sedimenting species must be accurately known in order to relate measured buoyant molecular weights to the stoichiometries and association constants of those self-associating species [26]. The $\bar{v}$ of nucleic acids is dependent on buffer conditions and values vary across a much wider range than those for proteins [20, 27]. It is therefore especially important to measure the $\bar{v}$ of pRNA to determine the association constants of multimeric pRNA. The $\bar{v}$ values have generally been measured using densimetric studies [28,29]. However, these methods require quantities of macromolecule that are beyond the reasonable scope of RNA produced by in vitro transcription or chemical synthesis. As alternatives, two methods using the analytical ultracentrifuge have been employed.

The first method makes use of the difference in solvent densities for $\mathrm{H}_{2} \mathrm{O}$ and $\mathrm{D}_{2} \mathrm{O}$-based buffers [30]. It can be seen from equation (1) that the buoyant molecular weight, $M_{\mathrm{b}}$, measured by equilibrium sedimentation depends on solvent density $\rho_{0}$ :

$$
M_{\mathrm{b}}=M\left(1-\bar{v} \rho_{0}\right)
$$

where $M$ is the solute molecular weight, $\bar{v}$ is the partial specific volume and $\rho_{0}$ is the solvent density. Two different solvent densities will give two different $M_{\mathrm{b}}$ values for a species with a mass $M$, allowing elucidation of $\bar{v}$ using simultaneous equations.

Three 120pRNA samples were prepared at concentrations of 80,200 and $325 \mathrm{nM}$ in $\mathrm{H}_{2} \mathrm{O}$ and $\mathrm{D}_{2} \mathrm{O}$ buffers $(50 \mathrm{mM}$ Tris- $\mathrm{HCl} \mathrm{pH} 7.0,330 \mathrm{mM} \mathrm{NaCl}, 0.1 \mathrm{mM}$ EDTA). The densities of the buffers at $14^{\circ} \mathrm{C}$ were calculated using the Sednterp software. The samples were used in equilibrium sedimentation experiments at $14^{\circ} \mathrm{C}$ with rotor speeds of 12,000, 16,000 and 18,000 rpm. Absorbance profiles were recorded at $260 \mathrm{~nm}$. Buffers did not include $\mathrm{MgCl}_{2}$ to reduce self-association of pRNA, minimising the complication of multiple molecular species adopting different distributions in the centrifuge.

The acquired absorbance profile was of steeper gradient for the less dense buffer $\left(\mathrm{H}_{2} \mathrm{O}\right)$, indicating a greater $M_{\mathrm{b}}$ as described in equation (1). The data for 120pRNA in each buffer were fitted to a single molecular species model to obtain values for $M_{\mathrm{b}}$. In $\mathrm{H}_{2} \mathrm{O}$ buffer
$M_{\mathrm{b}}=26,488 \mathrm{Da}(26,155,26,825 \mathrm{Da})$, with $95 \%$ confidence intervals given in brackets. In $\mathrm{D}_{2} \mathrm{O}$ buffer, $M_{\mathrm{b}}=24,552 \mathrm{Da}(24,274,24,833 \mathrm{Da})$. Inputting these values, and the confidence intervals as the associated errors, into equation (1) yields $\bar{v}=0.47 \pm 0.10 \mathrm{ml} / \mathrm{g}$ for 120pRNA. The error in this value is due to the dependency of $\bar{v}$ on the difference in the two buoyant molecular weights. Since the change in density of the solvents was not great enough to give a large difference in $M_{\mathrm{b}}$, the error in $\bar{v}$ is large.

Using these buoyant molecular weight and $\bar{v}$ values, it was possible to calculate the molecular weight $M$ for 120 pRNA to be $50.0 \mathrm{kDa}$. However, based on the sequence and mass spectrometry data the molecular mass is $38.7 \mathrm{kDa}$. It is therefore evident that some selfassociation is occurring in solution, even in the absence of magnesium ions in the buffer. In contrast, if it is assumed that self-association is not occurring, by applying a molecular mass of $38.7 \mathrm{kDa}$ and $M_{\mathrm{b}}$ of $26,488 \mathrm{Da}$ (in $\mathrm{H}_{2} \mathrm{O}$ buffers, see above) to equation (1), $\bar{v}$ is calculated to be $0.291 \mathrm{ml} / \mathrm{g}$, a value outside the range expected for RNA.

The second method for the determination of $\bar{v}$ by AUC uses the pRNA mutant 71F6pRNA (figure 1(B)) [7, 31]. As 71F6pRNA is non-multimerising and will therefore be present as a solely monomeric species, the $M_{\mathrm{b}}$ measured by equilibrium sedimentation and the molecular weight of 71F6pRNA determined by electrospray ionisation mass spectrometry can be used to find $\bar{v}$ by equation (1).

Samples of 71F6pRNA at concentrations of $0.5,1.5,2.5$, 4.3 and $13.0 \mu \mathrm{M}$ were prepared in aqueous buffer $(50 \mathrm{mM}$ Tris- $\mathrm{HCl} \mathrm{pH} 7.0,300 \mathrm{mM} \mathrm{NaCl}, 10 \mathrm{mM} \mathrm{MgCl}_{2}, 0.1 \mathrm{mM}$ EDTA) and analysed in an equilibrium sedimentation experiment at $14^{\circ} \mathrm{C}$ with rotor speeds of $10,000,13,000$ and $18,000 \mathrm{rpm}$. Absorbance profiles were recorded at $290 \mathrm{~nm}$. A single molecular species was used to model all absorbance distributions for the 71F6pRNA samples. The model describes the data well, giving a value of $M_{\mathrm{b}}=12,576 \mathrm{Da}$ (12,501, 12,651 Da) (see figure 2(A) for absorbance profiles, together with the results of model fitting). Using this value of $M_{\mathrm{b}}$, the density of the buffer, and the molecular weight of $71 \mathrm{~F} 6 \mathrm{pRNA}, \quad M=23,329 \mathrm{Da}$ as determined by electrospray mass spectrometry, affords $\bar{v}=0.455 \pm$ $0.003 \mathrm{ml} / \mathrm{g}$. This value corresponds closely to that determined for 120pRNA by the difference in solvent densities method as described above, but in this case with very low error.

The importance of determining $\bar{v}$ for a particular RNA species, rather than using a general literature-sourced $\bar{v}$ value, can be seen when $M$ is calculated for $71 \mathrm{~F} 6 \mathrm{pRNA}$ from equation (1), using $M_{\mathrm{b}}$ and $\rho_{0}$ values from this study in combination with $\bar{v}$ values at each end of the range reported in the literature $(0.46-0.58 \mathrm{ml} / \mathrm{g}$ [20]). Under these conditions, $M$ is calculated to be in the range 23,570-30,533 Da (compared to the experimental value $M=23,329 \mathrm{Da}$ for $71 \mathrm{~F} 6 \mathrm{pRNA}$ ). This clearly demonstrates that significant errors in values of $M$ could result if 
A

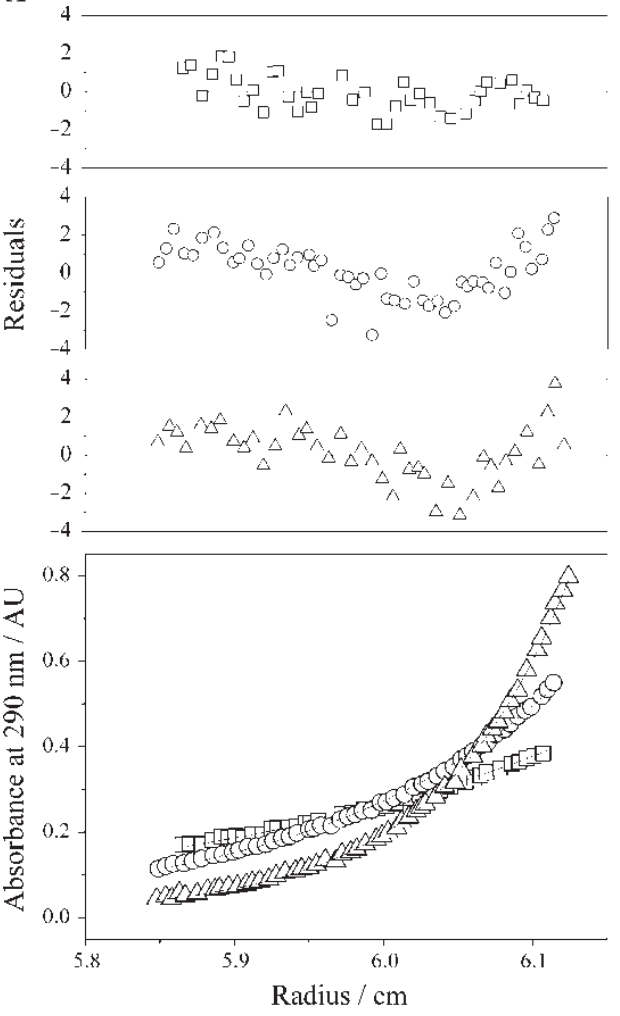

B
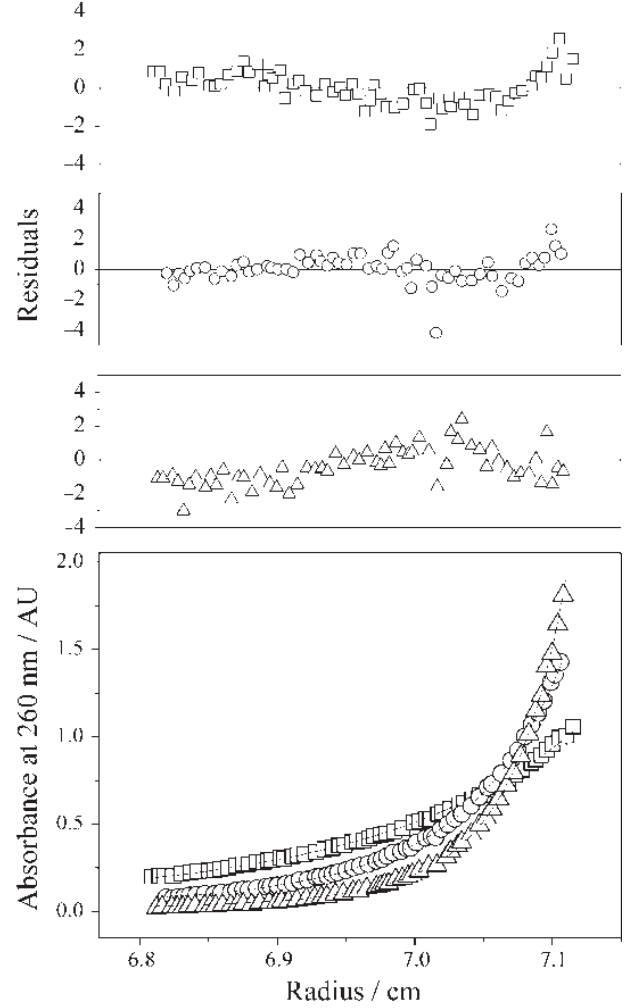

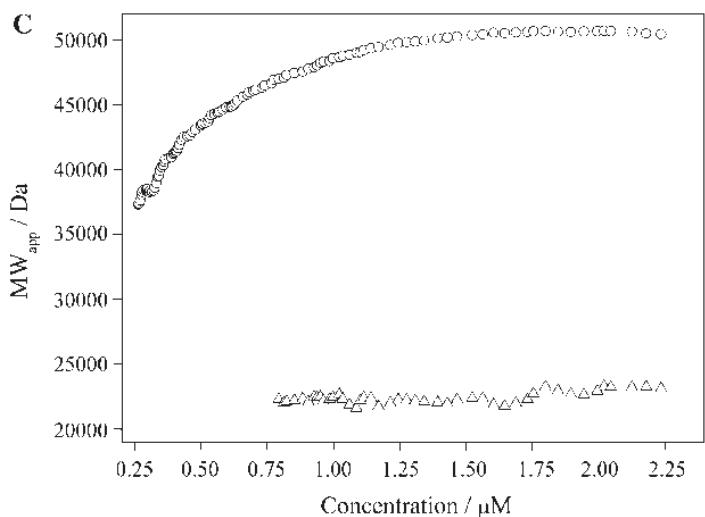

Figure 2. Equilibrium sedimentation data for 71F6pRNA (A), initial concentration $2.5 \mu \mathrm{M}$, was fitted to a single species model at rotor speeds of 10,000 (squares), 13,000 (circles) and 18,000 rpm (triangles). The absorbance values at $290 \mathrm{~nm}$ for each rotor speed are shown as individual data points (every third data point is shown for clarity). A global fit to all data at each rotor speed is shown as solid lines, with residuals indicating no significant systematic deviation from zero. $M_{\mathrm{b}}=12,576$ Da. Equilibrium sedimentation data for $120 \mathrm{pRNA}$ (B), initial concentration $1.0 \mu \mathrm{M}$ plus $10 \mathrm{mM} \mathrm{MgCl}_{2}$ was fitted to a reversible self-association model incorporating monomer-dimer-trimer species at rotor speeds of 7000 (squares), 10,000 (circles) and $13,000 \mathrm{rpm}$ (triangles). The absorbance values at $260 \mathrm{~nm}$ for each rotor speed are shown as individual data points (every third data point is shown for clarity). A global fit to all data at each rotor speed is shown as solid lines, with residuals indicating no significant systematic deviation from zero. The concentration dependence of apparent molecular weight $\left(M_{\mathrm{app}}\right)$ for $71 \mathrm{~F} 6 \mathrm{pRNA}$ and $71 \mathrm{pRNA}$ was determined by equilibrium sedimentation experiments (C). In the case of $71 \mathrm{~F} 6 \mathrm{pRNA}$ (triangles), $M_{\mathrm{app}}$ is constant at a value of $M_{\mathrm{app}} \approx 23 \mathrm{kDa}$, whereas for $71 \mathrm{pRNA}$ (circles), $M_{\text {app }}$ increases as a function of concentration. This increase of $M_{\text {app }}$ from 37 to $50 \mathrm{kDa}$ is indicative of a self-associating system.

an inappropriate $\bar{v}$ value is used in analysis of data from AUC experiments.

\subsection{Solution behaviour of pRNA species}

Having determined the partial specific volume of pRNA $(\bar{v}=0.455 \mathrm{ml} / \mathrm{g})$, the self-association of 71pRNA and 120pRNA was investigated using equilibrium sedimentation experiments. Three 120pRNA samples in buffer $(50 \mathrm{mM}$
Tris- $\mathrm{HCl} \mathrm{pH} 7.0,300 \mathrm{mM} \mathrm{NaCl}, 10 \mathrm{mM} \mathrm{MgCl}, 0.1 \mathrm{mM}$ EDTA) at concentrations between 0.1 and $1.0 \mu \mathrm{M}$ were used in equilibrium sedimentation experiments at $14^{\circ} \mathrm{C}$ with rotor speeds of 5000, 7000, 10,000 and 13,000 rpm. Absorbance profiles were recorded at $260 \mathrm{~nm}$ (figure 2(B)). An analogous experiment was carried out with samples of 71pRNA between 0.2 and $1.5 \mu \mathrm{M}$.

The data for 71pRNA and 120pRNA did not fit well to a single species model, but could be modelled in terms of 
a self-association model including monomer, dimer and trimer species. Our experiments using size-exclusion chromatography with on-line light scattering detection have shown that only these molecular species are present in solution [31]. In addition, it has been shown that pRNA dimers and trimers are competent to bind proheads in vitro [32]. Table 1 shows the self-association constants determined by the model fitting for 71pRNA and 120pRNA. The association constants for the 71pRNA and 120pRNA species in the presence of magnesium ions are very similar $\left(K_{\mathrm{A} 1,2}=6.4 \times 10^{6}\right.$ and $3.8 \times 10^{6} \mathrm{M}^{-1}$, respectively). The A helix, which is present in 120pRNA but shortened in 71pRNA, appears to have little or no effect on the self-association. In the absence of magnesium ions, there is approximately a 25-fold decrease in association constant for $71 \mathrm{pRNA}$ $\left(K_{\mathrm{A} 1,2}=2.6 \times 10^{5} \mathrm{M}^{-1}\right)$, indicating the strong magnesium ion dependency of this process.

The solution behaviour of 71pRNA was assessed by transforming the equilibrium sedimentation data to give the relationship between apparent molecular weight, $M_{\text {app }}$, and concentration. Figure 2(C) shows this relationship for 71pRNA with a loading concentration of $1.5 \mu \mathrm{M}$ at $13,000 \mathrm{rpm}$ and $14^{\circ} \mathrm{C}$. To allow contrast with a system where multimerisation does not occur, analogous data for $71 \mathrm{~F} 6 \mathrm{pRNA}$ is included. The initial loading concentration of 71F6pRNA was $2.5 \mu \mathrm{M}$ and the absorbance distribution at $290 \mathrm{~nm}$ was measured. It can be seen that the apparent molecular weight of $71 \mathrm{~F} 6 \mathrm{pRNA}$ remains constant $\left(M_{\text {app }} \approx 23 \mathrm{kDa}\right)$ as a function of increasing concentration, suggesting that there is no self-association. In contrast, 71pRNA shows a greater initial $M_{\text {app}}$, which increases as a function of concentration $\left(M_{\mathrm{app}} \approx 37 \rightarrow 50 \mathrm{kDa}\right)$; the shape of this relationship is characteristic of reversible selfassociation. A similar increase in $M_{\text {app }}$ as a function of increasing concentration is observed for $120 \mathrm{pRNA}$.

\subsection{DNA probes of multimerisation}

In order to probe the pRNA regions thought to be involved in self-association, antisense DNA oligonucleotides were combined with 71pRNA in equilibrium sedimentation experiments. Three DNA oligonucleotides were designed to bind to different elements of the 71pRNA secondary structure (figure 3(A)): CE loop DNA (5'-GGTTTAATC-3') is antisense to the CE loop; D loop DNA ( $5^{\prime}$-ACAACCAAT$\left.3^{\prime}\right)$ is antisense to the D loop; and CE helix DNA (5'GTGGGCTGA- $3^{\prime}$ ) is antisense to part of the $\mathrm{C}$ and $\mathrm{E}$ helices, an area implicated in inter-pRNA association in a chemical crosslinking study. A fourth DNA oligonucleotide, $7 \mathrm{mer}$ DNA (5'-CTTCCTT-3'), with minimal complementarity to 71pRNA was used as a control.

Samples of $0.4 \mu \mathrm{M} 71 \mathrm{pRNA}$ with different concentrations $(0.4,0.8,1.25,2$ and $4 \mu \mathrm{M})$ of each of the DNA inhibitors in aqueous buffer $(50 \mathrm{mM}$ Tris $-\mathrm{HCl} \mathrm{pH} 7.0$, $300 \mathrm{mM} \mathrm{NaCl}, 10 \mathrm{mM} \mathrm{MgCl}_{2}, 0.1 \mathrm{mM}$ EDTA) were prepared. One sample of $0.4 \mu \mathrm{M} 71 \mathrm{pRNA}$ alone was also prepared to act as an initial $M$ control. These samples were analysed in equilibrium sedimentation experiments at $14^{\circ} \mathrm{C}$ with rotor speeds of 5000, 7000, 10,000 and $13,000 \mathrm{rpm}$. Absorbance profiles were recorded at $282 \mathrm{~nm}$. The use of DNA oligonucleotides that can intermolecularly base pair with 71pRNA greatly increases the number of possible species in the AUC cell. Rather than analysing the data using a self-association model including multimeric 71pRNA, a single-species fit was used for each concentration of DNA probe as an interpretation of the data. A value of $\bar{v}=0.455 \mathrm{ml} / \mathrm{g}$ was used for all sedimenting molecular species. Unbound DNA probe, which should not sediment appreciably at these rotor speeds, was removed from the analysis by including the baseline offset as a fitting parameter.

Figure 3(B) shows the molecular weight, $M$, returned by single-species fits to equilibrium sedimentation data for 71pRNA and the 4 DNA oligonucleotides, with error bars indicating $95 \%$ confidence intervals. The molecular weight fit for $71 \mathrm{pRNA}$ alone is $48,053 \mathrm{Da}$ (figure 3(B), solid square). Since the monomeric molecular weight of 71pRNA is $22,966 \mathrm{Da}$, the application of a single-species model affords a value that reflects the multimeric species present in solution. The introduction of the control 7mer DNA (figure 3(B), hollow square) to 71pRNA has no significant effect on $M$, indicating that with little sequence complementarity to $71 \mathrm{pRNA}$, the 7 mer DNA probe is not able to interact with 71pRNA, in a way that inhibits self-association.

CE loop DNA (figure 3(B), cross) has a marked effect on $M$, even at a concentration of $0.4 \mu \mathrm{M}$. Interestingly, at a concentration of $4 \mu \mathrm{M}$, a ten-fold excess over the 71pRNA concentration, $M=21,461 \mathrm{Da}$. This value is close to the molecular weight of monomeric 71pRNA, indicating that self-association of 71pRNA has been prevented. The inhibitory effect of the CE loop DNA probe is likely to be the result of base pairing to the CE loop of 71pRNA, preventing pRNA self-association through CE-D loop interactions.

D loop DNA (figure 3(B), circle) has a much reduced effect on $M$ in comparison to CE loop DNA, although the

Table 1. The association constants (with $95 \%$ confidence intervals in brackets) for monomer to dimer $\left(K_{\mathrm{A} 1,2}\right)$ and monomer to trimer $\left(K_{\mathrm{A} 1,3}\right)$ equilibria are displayed for $71 \mathrm{pRNA} \pm 10 \mathrm{mM} \mathrm{MgCl} 2$ and $120 \mathrm{pRNA}+10 \mathrm{mM} \mathrm{MgCl}_{2}$.

\begin{tabular}{lcr}
\hline RNA & $K_{\mathrm{A} 1,2} / \mathrm{M}^{-1}$ & \multicolumn{1}{c}{$K_{\mathrm{A} 1,3} / \mathrm{M}^{-2}$} \\
\hline 71pRNA & $2.6(2.3,2.9) \times 10^{5}$ & $1.5(1.4,1.6) \times 10^{11}$ \\
71pRNA + $10 \mathrm{mM} \mathrm{MgCl}_{2}$ & $6.4(5.3,7.8) \times 10^{6}$ & $1.5(1.3,1.8) \times 10^{13}$ \\
120pNA + $10 \mathrm{mM} \mathrm{MgCl}_{2}$ & $3.8(3.1,4.8) \times 10^{6}$ & $1.3(1.1,1.5) \times 10^{13}$ \\
\hline
\end{tabular}



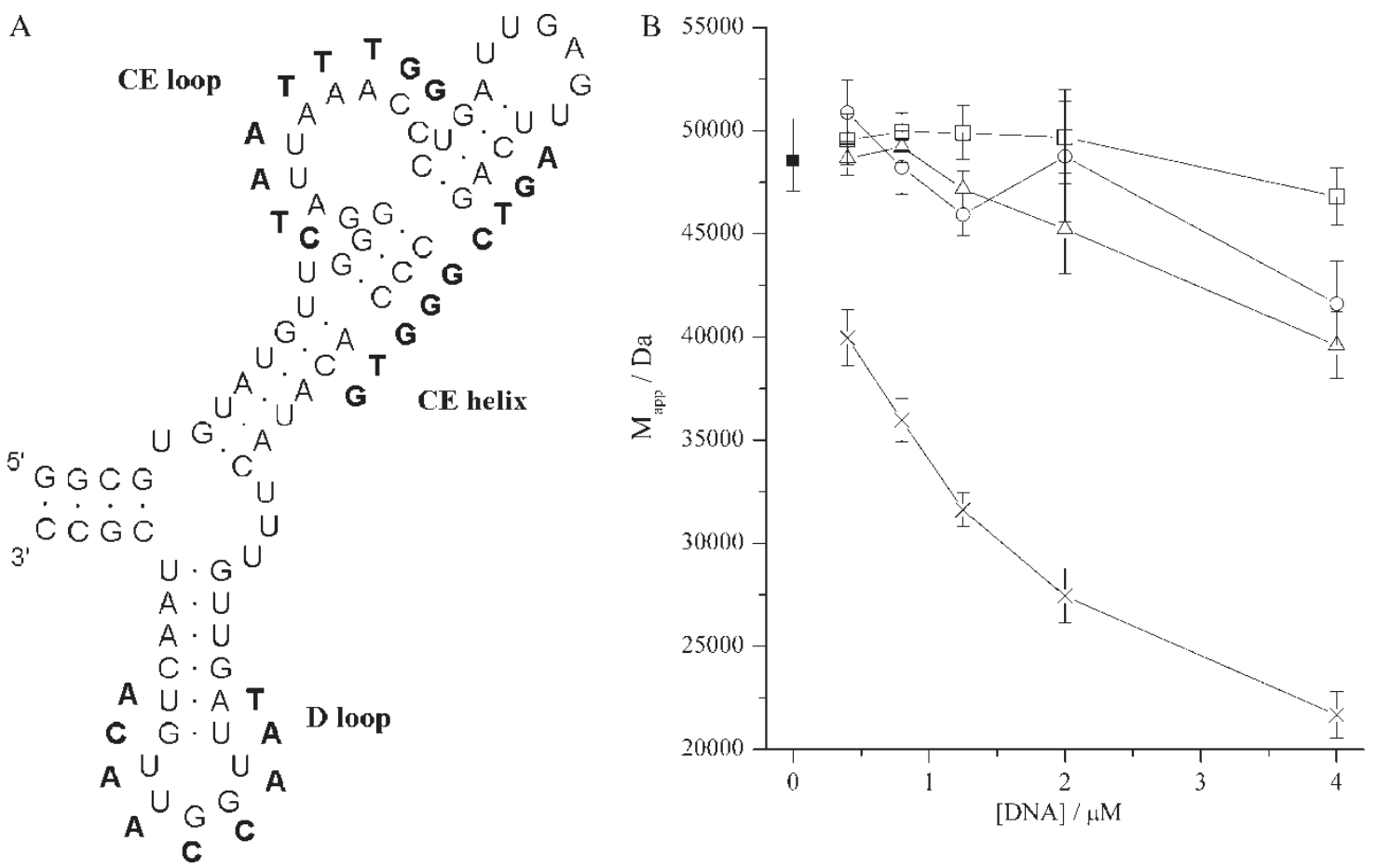

Figure 3. The proposed secondary structure of 71pRNA (A) with DNA probes of multimerisation CE loop, CE helix and D loop shown in bold Analysis of the effect of DNA probes on 71pRNA multimerisation was carried out by equilibrium sedimentation experiments in the analytical ultracentrifuge (B). Rotor speeds of 5000, 7000, 10,000 and 13,000 rpm, with an initial loading concentration of $0.4 \mu \mathrm{M} 71 \mathrm{pRNA}$, were used with DNA concentrations in the range $0.4-4 \mu \mathrm{M}$. The results of single species fits in each experiment, under a range of DNA concentrations, are given (CE loop, cross; D loop, circle; CE helix, triangle; random $7 \mathrm{mer}$, hollow square) with a control $M$ of $71 \mathrm{pRNA}$ alone (solid square). Addition of the CE loop probe resulted in a reduction of $M$ to a value equivalent to monomeric 71pRNA. D loop probe and CE helix probe had less marked effects on $M$ of $71 \mathrm{pRNA}$, but these changes represent greater inhibition than observed by the random sequence DNA control with little sequence complementarity to $71 \mathrm{pRNA}$.

effect is still apparent in comparison to 7mer DNA. This may suggest that the D loop of 71pRNA is less accessible for the binding of a DNA probe than the larger CE loop. Furthermore, CE loop DNA pairs to nine single-stranded nucleotides in the predicted secondary structure of 71pRNA, whereas D loop DNA is complementary to only five single-stranded nucleotides. The remaining four nucleotides in the sequence represent ribonucleotides involved in base-pairing in the stem of 71pRNA D loop. These bases are less likely to be available for interaction with the D loop DNA probe.

CE helix DNA (figure 3(B), triangle) has an effect on $M$ with similar magnitude to that of D loop DNA. The CE helix DNA probe has a sequence complementary to nucleotides in the $\mathrm{CE}$ and $\mathrm{E}$ helices of pRNA. In this case, the inhibition of pRNA self-association could arise from the disruption of the pRNA CE and E helices thereby producing a structure that no longer allows selfassociation, and/or the steric hindrance of self-association.

\section{Conclusions}

This paper reports a study into the multimerisation of bacteriophage $\$ 29$ pRNA using AUC. We have determined an accurate value of the partial specific volume for pRNA $(\bar{v}=0.455 \mathrm{ml} / \mathrm{g}$ ) by two independent methods and used this to define the solution state of the molecule, as well as of a multimerisation-incompetent variant. It is documented that magnesium ions are necessary for multimerisation [33]. From our data, it is clear that some self-association of 120pRNA molecules can occur even without the addition of magnesium ions into the experiment.

Based on light scattering data [31], we fitted the AUC data for 120pRNA and the truncated 71pRNA to a monomerdimer-trimer model. Although the data would also fit well to models incorporating higher-order species, we have no evidence to support the presence of species larger than trimer in solution. A previous study attempted to use AUC to determine the stoichiometry of pRNA multimers [16]. Data were fitted to a three-species model: monomer, dimer and hexamer, using an assumed value of $\bar{v}(0.588 \mathrm{ml} / \mathrm{g})$. The experiment was performed in a buffer of low ionic strength (10 mM Tris-HCl, pH 7.0, $10 \mathrm{mM} \mathrm{MgCl} 2,0.1 \mathrm{mM}$ EDTA). We found that experiments in similar buffers show characteristics typical of Donnan potentials. These electrostatic potentials can affect the concentration distribution of the RNA. In such non-ideal buffer conditions, data cannot be analysed in terms of a simple reversible association model, even if it is clear that some multimerisation is occurring [26].

From our data, we were able to calculate the affinity for the pRNA-pRNA interaction in solution. Although we demonstrated that pRNA can self-associate to an extent without addition of magnesium ions, it appears that the addition of $\mathrm{MgCl}_{2}$ increases the affinity of the pRNA-pRNA interaction by a factor of approximately 25 . The equilibrium 
sedimentation experiments with 71pRNA and DNA probes of multimerisation support the involvement of pRNA bases in the CE loop and in the D loop in self-association, and also (whether directly or indirectly) areas of the CE helix. These data may provide further insight into the structure of pRNA required for self-association and therefore competent DNA packaging in this molecular motor. In addition to promoting base-pairing, divalent magnesium ions have been proposed to lead to pRNA conformational change [31-34]. Results here are consistent with the hypothesis that the pRNA secondary structure (as shown in figure 1) does not represent the arrangement and conformation of the molecule in the active system, possibly due to a rearrangement of the three helix junction. An analogous magnesium ion dependent rearrangement of the three-helix junction of the VS ribozyme has been reported [35, 36]. Further studies will be necessary to determine if such a rearrangement occurs during DNA packaging by $\phi 29$.

\section{Acknowledgements}

This work was supported by the BBSRC (UK) 24/C17944 and the MRC (UK) G120/280. The authors wish to thank Dr A.E. Ashcroft (University of Leeds, UK) for mass spectrometry analysis, Dr C.J. Adams (University of Leeds, UK) for DNA synthesis and Prof P. Guo (Purdue University, US) for his encouragement and useful discussions.

\section{References}

[1] Stockley, P.G., Stonehouse, N.J. and Valegård, K., 1994, Molecular mechanism of RNA phage morphogenesis. Int. J. Biochem., 26, $1249-1260$

[2] Valegård, K., Murray, J.B., Stockley, P.G., Stonehouse, N.J. and Liljas, L., 1994, Crystal structure of an RNA bacteriophage coat protein operator complex. Nature, 371, 623-626.

[3] Valegård, K., Murray, J.B., Stonehouse, N.J., van den Worm, S., Stockley, P.G. and Liljas, L., 1997, The three-dimensional structures of two complexes between recombinant MS2 capsids and RNA operator fragments reveal sequence-specific protein-RNA interactions. J. Mol. Biol., 270, 724-738.

[4] Trus, B.L., Cheng, N., Newcomb, W.W., Homa, F.L., Brown, J.C. and Steven, A.C., 2004, Structure and polymorphism of the UL6 portal protein of Herpes Simplex Virus Type 1. J. Virol., 78, 12668-12671.

[5] Lee, C.-S. and Guo, P., 1995, In vitro assembly of infectious virions of double-stranded DNA phage $\phi 29$ from cloned gene products and synthetic nucleic acids. J. Virol., 69, 5018-5023.

[6] Guo, P., Bailey, S., Bodley, J.W. and Anderson, D., 1987, Characterization of the small RNA of the bacteriophage $\$ 29$ DNA packaging machine. Nucleic Acids Res., 15, 7081-7090.

[7] Reid, R., Zhang, F., Benson, S. and Anderson, D., 1994, Probing the structure of bacteriophage $\phi 29$ prohead RNA with specific mutations. J. Biol. Chem., 269, 18656-18661.

[8] Chen, C.P., Sheng, S.T., Shao, Z.F. and Guo, P., 2000, A dimer as a building block in assembling RNA-a hexamer that gears bacterial virus \$29 DNA-translocating machinery. J. Biol. Chem., 275, 17510-17516.

[9] Smith, D.E., Tans, S.J., Smith, S.B., Grimes, S., Anderson, D.L. and Bustamante, C., 2001, The bacteriophage $\phi 29$ portal motor can package DNA against a large internal force. Nature, 413, 748-752.

[10] Bailey, S., Wichitwechkarn, J., Johnson, D., Reilly, B., Anderson, D. and Bodley, J., 1990, Phylogenetic analysis and secondary structure of the Bacillus subtilis bacteriophage RNA required for DNA packaging. J. Biol. Chem., 265, 22365-22370.

[11] Guasch, A., Pous, J., Parraga, A., Valpuesta, J.M., Carrascosa, J.L. and Coll, M., 1998, Crystallographic analysis reveals the 12-fold symmetry of the bacteriophage $\phi 29$ connector particle. J. Mol. Biol., 281, 219-225.

[12] Valpuesta, J.M., Fernández, J.J., Carazo, J.M. and Carrascosa, J.L., 1999, The three-dimensional structure of a DNA translocating machine at $10 \AA$ resolution. Structure, 7, 289-296.

[13] Simpson, A.A., Tao, Y.Z., Leiman, P.G., Badasso, M.O., He, Y.N., Jardine, P.J., Olson, N.H., Morais, M.C., Grimes, S., Anderson, D.L., Baker, T.S. and Rossmann, M.G., 2000, Structure of the bacteriophage $\$ 29$ DNA packaging motor. Nature, 408, 745-750.

[14] Guasch, A., Parrága, A., Pous, J., Valpuesta, J.M., Carrascosa, J.L. and Coll, M., 1998, Purification, crystallization and preliminary Xray diffraction studies of the bacteriophage $\phi 29$ connector particle. FEBS Lett., 430, 283-287.

[15] Ibarra, B., Castón, J.R., Llorca, O., Valle, M., Valpuesta, J.M. and Carrascosa, J.L., 2000, Topology of the components of the DNA packaging machinery in the phage $\$ 29$ prohead. J. Mol. Biol., 298, 807-815.

[16] Zhang, F., Lemieux, S., Wu, X.L., StArnaud, D., McMurray, C.T., Major, F. and Anderson, D., 1998, Function of hexameric RNA in packaging of bacteriophage $\$ 29$ DNA in vitro. Mol. Cell, 2, 141-147.

[17] Hendrix, R.W., 1978, Symmetry mismatch and DNA packaging in large bacteriophages. PNAS, 75, 4779-4783.

[18] Serwer, P., 2003, Models of bacteriophage DNA packaging motors. J. Struct. Biol., 141, 179-188.

[19] Lebowitz, J., Lewis, M.S. and Schuck, P., 2002, Modern analytical ultracentrifugation in protein science: a tutorial review. Protein Sci., 11, 2067-2079.

[20] Durchschlag, H., 1989, Determination of the partial specific volume of conjugated proteins. Coll. Polymer Sci., 267, 1139-1150.

[21] Ortega, J.P. and Hill, W.E., 1973, A molecular weight determination of the 16S ribosomal ribonucleic acid from Escherichia coli. Biochemistry, 12, 3241-3243.

[22] Bovee, M.L., Yan, W., Sproat, B.S. and Francklyn, C.S., 1999, tRNA discrimination at the binding step by a Class II aminoacyltRNA synthetase. Biochemistry, 38, 13725-13735.

[23] Limbach, P.A., Crain, P.F. and McCloskey, J.A., 1995, Molecular mass measurements of intact ribonucleic acids via electrospray ionization quadrupole mass spectrometry. J. Am. Soc. Mass Spectrom., 6, 27-39.

[24] Laue, T., Shah, B., Ridgeway, T. and Pelletier, S., 1992, In: S.E. Harding, A.J. Rowe and J.C. Horton (Eds.) Analytical Ultracentrifugation in Biochemistry and Polymer Science (Cambridge: Royal Society of Chemistry).

[25] Murray, J.B., Collier, A.K. and Arnold, J.R.P., 1994, A general purification procedure for chemically synthesised oligoribonucleotides. Anal. Biochem., 218, 177-184.

[26] Tanford, C., 1961, Physical Chemistry of Macromolecules (New York: John Wiley and Sons).

[27] Eisenberg, H., 1994, Protein and nucleic-acid hydration and cosolvent interactions-establishment of reliable base-line values at high cosolvent concentrations. Biophys. Chem., 53, 57-68.

[28] Durchschlag, H. and Jaenicke, R., 1982, Partial specific volume changes of proteins: densimetric studies. Biochem. Biophys. Res. Commun., 108, 1074-1079.

[29] Ebel, C., Eisenberg, H. and Ghirlando, R., 2000, Probing proteinsugar interactions. Biophys. J., 78, 385-393.

[30] Edelstein, S.J. and Schachman, H.K., 1967, The simultaneous determination of partial specific volumes and molecular weights with microgram quantities. J. Biol. Chem., 242, 306-311.

[31] Robinson, M.A., Wood, J.P.A., Capaldi, S.A., Baron, A.J., Stonehouse, N.J., Manuscript in preparation.

[32] Trottier, M., Mat-Arip, Y., Zhang, C.L., Chen, C.P., Sheng, S.T., Shao, Z.F. and Guo, P., 2000, Probing the structure of monomers and dimers of the bacterial virus phi29 hexamer RNA complex by chemical modification. RNA, 6, 1257-1266.

[33] Guo, P., Zhang, C., Chen, C., Garver, K. and Trottier, M., 1998, Inter-RNA interaction of phage $\phi 29$ pRNA to form a hexameric complex for viral DNA transportation. Mol. Cell, 2, 149-155.

[34] Chen, C. and Guo, P., 1997, Magnesium-induced conformational change of packaging RNA for procapsid recognition and binding during phage $\$ 29$ DNA encapsidation. J. Virol., 71, 495-500.

[35] Lafontaine, D.A., Norman, D.G. and Lilley, D.M.J., 2001, Structure, folding and activity of the VS ribozyme: Importance of the 2-3-6 helical junction. EMBO J., 20, 1415-1424.

[36] Lafontaine, D.A., Norman, D.G. and Lilley, D.M.J., 2002, Folding and catalysis by the VS ribozyme. Biochimie, 84, 889-896. 


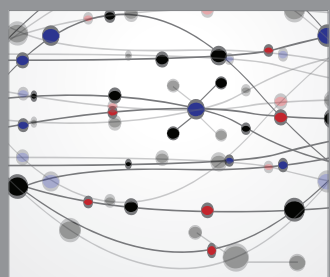

The Scientific World Journal
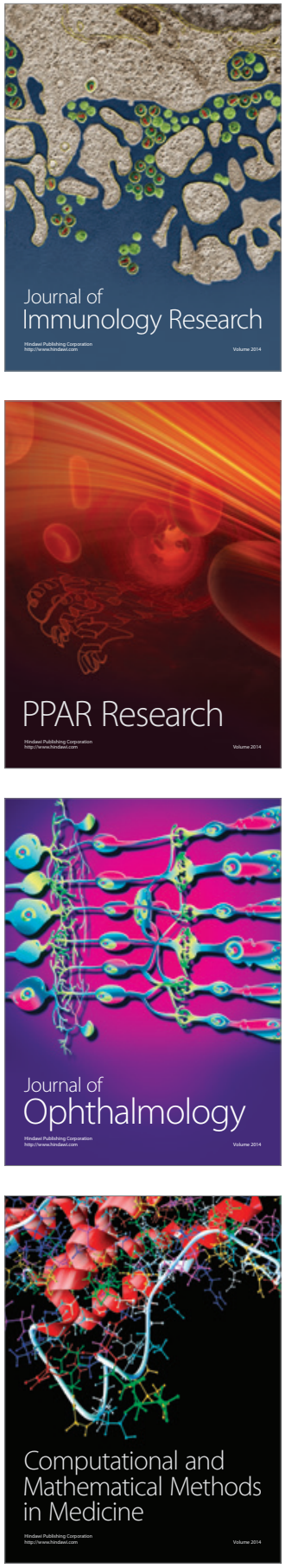

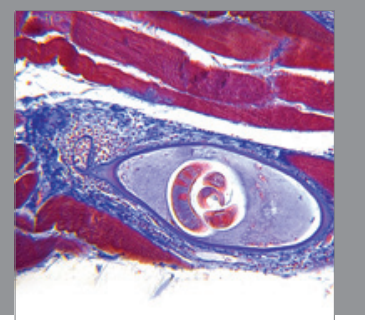

Gastroenterology

Research and Practice
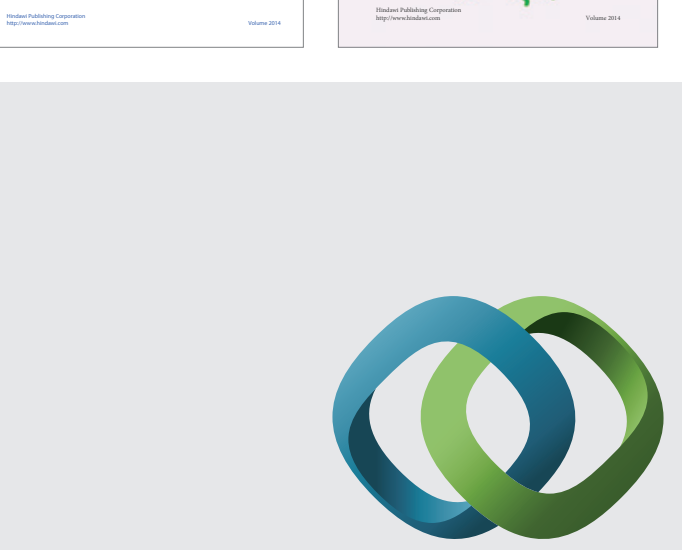

\section{Hindawi}

Submit your manuscripts at

http://www.hindawi.com
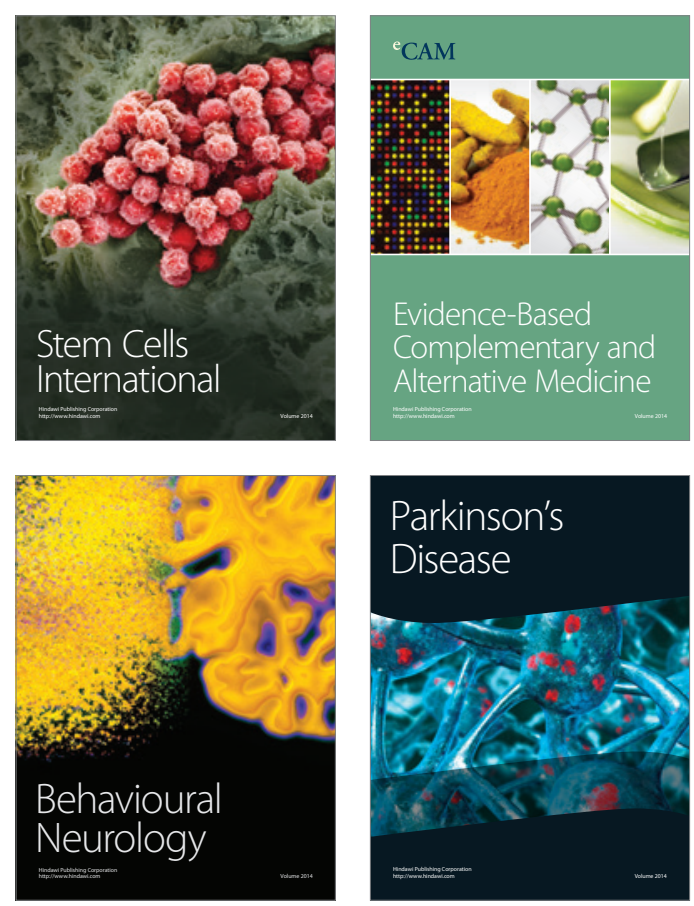

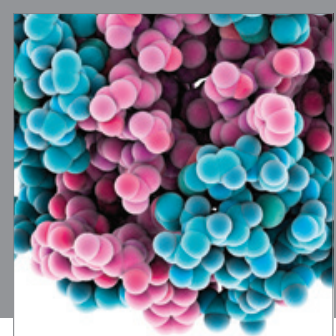

Journal of
Diabetes Research

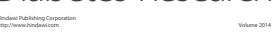

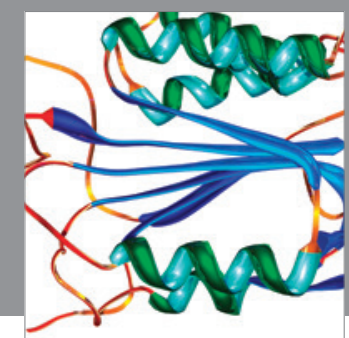

Disease Markers
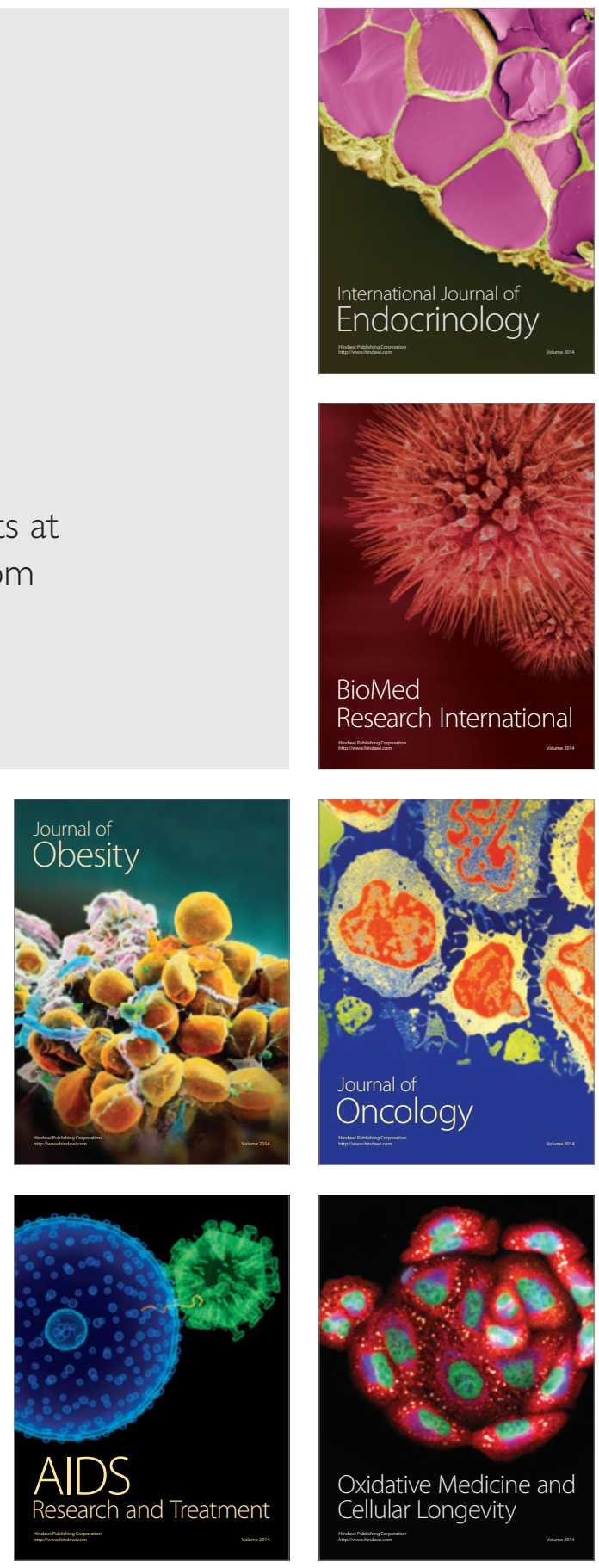